\title{
A generalization of Geraghty's theorem in partially ordered metric spaces and applications to ordinary differential equations
}

\author{
Madjid Eshaghi Gordji ${ }^{1}$, Maryam Ramezani ${ }^{1}$, Yeol Je Cho $^{2^{*}}$ and Saeideh Pirbavafa ${ }^{1}$
}

\author{
* Correspondence: yjcho@gnu.ac.kr \\ ${ }^{2}$ Department of Mathematics \\ Education and the RINS, \\ Gyeongsang National University, \\ Chinju 660-701, Korea \\ Full list of author information is \\ available at the end of the article
}

\begin{abstract}
The purpose of this article is to present some fixed point theorems for generalized contraction in partially ordered complete metric spaces. As an application, we give an existence and uniqueness for the solution of an initial-boundary-value problem. 2000 Mathematics Subject Classification: 47H10; 54H25; 34B15.
\end{abstract}

Keywords: fixed point, partially ordered metric spaces, contraction, initial-value problem

\section{Introduction and preliminaries}

Banach's contraction principle is one of the pivotal results of analysis. It is widely considered as the source of metric fixed point theory. Also, its significance lies in its vast applicability in a number of branches of mathematics. The existence of a fixed point, a common fixed point and a couple fixed point for some kinds of contraction type mappings in cone metric spaces, partially ordered metric spaces and fuzzy metric spaces has been considered recently by some authors [1-28] and, by using fixed point theorems, some of them have given some applications to matrix equations, ordinary diffierential equations, and integral equations are presented.

Let $S$ denotes the class of the functions $\beta:[0, \infty) \rightarrow[0,1)$ which satisfies the condition $\beta\left(t_{n}\right) \rightarrow 1$ implies $t_{n} \rightarrow 0$.

The following generalization of Banach's contraction principle is due to Geraghty [13].

Theorem 1.1. Let $(X, d)$ be a complete metric space and $f: X \rightarrow X$ be a mapping such that there exists $\beta \in S$ such that, for all $x, y \in X$,

$$
d(f(x), f(y)) \leq \beta(d(x, y)) d(x, y)
$$

Then $f$ has a unique fixed point $z \in X$ and, for any choice of the initial point $x_{0} \in X$, the sequence $\left\{x_{n}\right\}$ defined $x_{n}=f\left(x_{n-1}\right.$ for each $n \geq 1$ converges to the point $z$.

Very recently, Amini-Harandi and Emami [3] proved the following existence theorem:

Theorem 1.2. Let $(X, \leq)$ be a partially ordered set and suppose that there exists a metric $d$ in $X$ such that $(X, d)$ is a complete metric space. Let $f: X \rightarrow X$ be an increasing mapping such that there exists $x_{0} \in X$ with $x_{0} \leq f\left(x_{0}\right)$. Suppose that there exists $\beta$

(C) 2012 Gordji et al; licensee Springer. This is an Open Access article distributed under the terms of the Creative Commons Attribution License (http://creativecommons.org/licenses/by/2.0), which permits unrestricted use, distribution, and reproduction in any medium, provided the original work is properly cited. 
$\in$ S such that

$$
d(f(x), f(y)) \leq \beta(d(x, y)) d(x, y)
$$

for all $x, y \in X$ with $x \geq y$. Assume that either $f$ is continuous or $X$ is such that if an increasing sequence $\left\{x_{n}\right\}$ converges to $x$, then $x_{n} \leq x$ for each $n \geq 1$.

Besides, if

for all $x, y \in X$, there exists $z \in X$ which is comparable to $x$ and $y$.

Then $f$ has a unique fixed point in $X$.

In this article, we give a generalization of Theorem 1.2 in the context of partially ordered complete metric spaces. Moreover, by using our result, we show the existence of solution for the following initial-value problem:

$$
\left\{\begin{array}{lc}
u_{t}(x, t)=u_{x x}(x, t)+F\left(x, t, u, u_{x}\right), & -\infty<x<\infty, 0<t \leq T, \\
u(x, 0)=\varphi(x), & -\infty<x<\infty,
\end{array}\right.
$$

where we assume that $\phi$ is continuously differentiable and $\phi, \phi^{\prime}$ are bounded and $F$ : $\mathbb{R} \times I \times \mathbb{R} \times \mathbb{R} \rightarrow \mathbb{R}$ with $F\left(x, t, u, u_{x}\right)$ is a continuous function.

\section{The main results}

We begin with the following auxiliary lemma which is useful to prove some fixed point theorems in various spaces (see [25]):

Lemma 2.1. Let $(X, d)$ be a metric space and $\left\{x_{n}\right\}$ be a sequence in $X$ such that $\left\{d\left(x_{n}\right.\right.$ $\left.\left.{ }_{+1}, x_{n}\right)\right\}$ is decreasing and

$$
\lim _{n \rightarrow \infty} d\left(x_{n+1}, x_{n}\right)=0 .
$$

If $\left\{x_{2 n}\right\}$ is not a Cauchy sequence, then there exist $\varepsilon>0$ and two sequences $\left\{m_{k}\right\},\left\{n_{k}\right\}$ of positive integers such that the following four sequences tend to $\varepsilon$ as $k \rightarrow \infty$ :

$$
\left\{d\left(x_{2 m_{k}}, x_{2 n_{k}}\right)\right\},\left\{d\left(x_{2 m_{k}}, x_{2 n_{k}+1}\right)\right\},\left\{d\left(x_{2 m_{k}-1}, x_{2 n_{k}}\right)\right\},\left\{d\left(x_{2 m_{k}-1}, x_{2 n_{k}+1}\right)\right\} .
$$

Let $\Psi$ denotes the class of the functions $\psi:[0, \infty) \rightarrow[0, \infty)$ which satisfies the following conditions:

(a) $\psi$ is nondecreasing;

(b) $\psi$ is sub-additive, that is, $\psi(s+t) \leq \psi(s)+\psi(t)$;

(c) $\psi$ is continuous;

(d) $\psi(t)=0 \Leftrightarrow t=0$.

We are now ready to state and prove our main theorem.

Theorem 2.2. Let $(X, \leq)$ be a partially ordered set and suppose that there exists a metric $d$ in $X$ such that $(X, d)$ is a complete metric space. Let $f: X \rightarrow X$ be a nondecreasing mapping such that there exists $x_{0} \in X$ with $x_{0} \leq f\left(x_{0}\right)$. Suppose that there exist $\beta \in S$ and $\psi \in \Psi$ such that

$$
\psi(d(f(x), f(y))) \leq \beta(\psi(d(x, y))) \psi(d(x, y))
$$

for all $x, y \in X$ with $x \geq y$. Assume that either $f$ is continuous or $X$ is such that

$$
\text { if an increasing sequence }\left\{x_{n}\right\} \text { converges to } x_{\text {, then }} x_{n} \leq x \text { for each } n \geq 1 \text {. }
$$

Then $f$ has a fixed point. 
Proof. Since $x_{0} \leq f\left(x_{0}\right)$ and $f$ is a nondecreasing function, we obtain, by induction, that

$$
x_{0} \leq f\left(x_{0}\right) \leq f^{2}\left(x_{0}\right) \leq f^{3}\left(x_{0}\right) \leq \cdots \leq f^{n}\left(x_{0}\right) \leq f^{n+1}\left(x_{0}\right) \leq \cdots .
$$

Put $x_{n}:=f^{n}\left(x_{0}\right)$ for each $n \geq 1$. Since $x_{n} \leq x_{n+1}$ for each $n \geq 1$, by (2.1), we have

$$
\begin{aligned}
\psi\left(d\left(x_{n+1}, x_{n+2}\right)\right) & =\psi\left(d\left(f^{n+1}\left(x_{0}\right), f^{n+2}\left(x_{0}\right)\right)\right) \\
& \leq \beta\left(\psi\left(d\left(x_{n}, x_{n+1}\right)\right)\right) \psi\left(d\left(x_{n}, x_{n+1}\right)\right) \\
& \leq \psi\left(d\left(x_{n}, x_{n+1}\right)\right) .
\end{aligned}
$$

Thus it follows that $\left\{\psi\left(d\left(x_{n}, x_{n+1}\right)\right)\right\}$ is a nonincreasing sequence and bounded below and so $\lim _{n \rightarrow \infty} \psi\left(d\left(x_{n}, x_{n+1}\right)\right)=r$ exists. Let $\lim _{n \rightarrow \infty} \psi\left(d\left(x_{n}, x_{n+1}\right)\right)=r \geq 0$. Assume $r$ $>0$. Then, from (2.1), we have

$$
\frac{\psi\left(d\left(x_{n+1}, x_{n+2}\right)\right)}{\psi\left(d\left(x_{n}, x_{n+1}\right)\right)} \leq \beta\left(\psi\left(d\left(x_{n}, x_{n+1}\right)\right)\right) \leq 1
$$

for each $n \geq 1$, which yields that

$$
\lim _{n \rightarrow \infty} \beta\left(\psi\left(d\left(x_{n}, x_{n+1}\right)\right)\right)=1 .
$$

On the other hand, since $\beta \in S$, we have $\lim _{n \rightarrow \infty} \psi\left(d\left(x_{n}, x_{n+1}\right)\right)=0$ and so $r=0$.

Now, we show that $\left\{x_{n}\right\}$ is a Cauchy sequence. Suppose that $\left\{x_{n}\right\}$ is not a Cauchy sequence. Using Lemma 2.1, we know that there exist $\varepsilon>0$ and two sequences $\left\{m_{k}\right\}$ and $\left\{n_{k}\right\}$ of positive integers such that the following four sequences tend to $\varepsilon$ as $k \rightarrow \infty$ :

$$
\left\{d\left(x_{2 m_{k}}, x_{2 n_{k}}\right)\right\},\left\{d\left(x_{2 m_{k}}, x_{2 n_{k}+1}\right)\right\},\left\{d\left(x_{2 m_{k}-1}, x_{2 n_{k}}\right)\right\},\left\{d\left(x_{2 m_{k}-1}, x_{2 n_{k}+1}\right)\right\} .
$$

Putting, in the contractive condition, $x=x_{2 m_{k}-1}$ and $y=x_{2 n_{k}}$, it follows that

$$
\begin{aligned}
\psi\left(d\left(x_{2 m_{k}}, x_{2 n_{k}+1}\right)\right) & \leq \beta\left(\psi\left(d\left(x_{2 m_{k}-1}, x_{2 n_{k}}\right)\right)\right) \psi\left(d\left(x_{2 m_{k}-1}, x_{2 n_{k}}\right)\right) \\
& \leq \psi\left(d\left(x_{2 m_{k}-1}, x_{2 n_{k}}\right)\right)
\end{aligned}
$$

and so

$$
\frac{\psi\left(d\left(x_{2 m_{k}}, x_{2 n_{k}+1}\right)\right)}{\psi\left(d\left(x_{2 m_{k}-1}, x_{2 n_{k}}\right)\right.} \leq \beta\left(\psi\left(d\left(x_{2 m_{k}-1}, x_{2 n_{k}}\right)\right)\right) \leq 1
$$

and

$$
\lim _{k \rightarrow \infty} \beta\left(\psi\left(d\left(x_{2 m_{k}-1}, x_{2 n_{k}}\right)\right)\right)=1 .
$$

Since $\beta \in S$, it follows that $\lim _{k \rightarrow \infty} \psi\left(d\left(x_{2 m_{k}-1}, x_{2 n_{k}}\right)\right)=0$. Since $\psi$ is a continuous mapping, $\psi(\varepsilon)=0$ and so $\varepsilon=0$, which contradicts $\varepsilon>0$. Therefore, $\left\{x_{n}\right\}$ is a Cauchy sequence in $(X, d)$. Since $(X, d)$ is a complete metric space, there exists $z \in X$ such that $\lim _{n \rightarrow \infty} x_{n}=z$.

Now, we show that $z$ is a fixed point of $f$.

If $f$ is continuous, then

$$
z=\lim _{n \rightarrow \infty} f^{n}\left(x_{0}\right)=\lim _{n \rightarrow \infty} f^{n+1}\left(x_{0}\right)=f\left(\lim _{n \rightarrow \infty} f^{n}\left(x_{0}\right)\right)=f(z)
$$


and hence $f(z)=z$.

If (2.2) holds, then we have

$$
d(f(z), z) \leq d\left(f(z), f\left(x_{n}\right)\right)+d\left(f\left(x_{n}\right), z\right) .
$$

On the other hand, since $\psi$ is nondecreasing and sub-additive, we have

$$
\begin{aligned}
\psi(d(f(z), z)) & \leq \psi\left(d\left(f(z), f\left(x_{n}\right)\right)\right)+\psi\left(d\left(f\left(x_{n}\right), z\right)\right) \\
& \leq \beta\left(\psi\left(d\left(z, x_{n}\right)\right)\right) \psi\left(d\left(z, x_{n}\right)\right)+\psi\left(d\left(x_{n+1}, z\right)\right) \\
& \leq \psi\left(d\left(z, x_{n}\right)\right)+\psi\left(d\left(x_{n+1}, z\right)\right) .
\end{aligned}
$$

Since $d\left(z, x_{n}\right) \rightarrow 0, \psi\left(d\left(z, x_{n}\right)\right) \rightarrow 0$ and so

$$
\psi(d(f(z), z))=0 \quad \Leftrightarrow \quad d(f(z), z)=0 .
$$

Therefore, we get $f(z)=z$. this completes the proof. $\square$

In the following, we give a sufficient condition for the uniqueness of the fixed point in Theorem 2.2. This condition is as follows:

every pair of elements in X has a lower bound or an upper bound.

In [20], it is proved that the condition (2.3) is equivalent to the following:

$$
\text { for every } x, y \in X \text {, there exists } z \in X \text { which is comparable to } x \text { and } y \text {. }
$$

Theorem 2.3. Adding the condition (2.4) to the hypotheses of Theorem 2.2, the fixed point $z$ of $f$ is unique.

Proof. Let $y$ be another fixed point of $f$. From (2.4), there exists $x \in X$ which is comparable to $y$ and $z$. The monotonicity implies that $f^{\prime}(x)$ is comparable to $f^{\imath}(y)=y$ and $f^{\imath}(z)=z$ for $n \geq 0$. Moreover, we have

$$
\begin{aligned}
\psi & \left(d\left(z, f^{n}(x)\right)\right)=\psi\left(d\left(f^{n}(z), f^{n}(x)\right)\right) \\
& =\psi\left(d\left(f\left(f^{n-1}(z)\right), f\left(f^{n-1}(x)\right)\right)\right) \\
& \leq \beta\left(\psi\left(d\left(f^{n-1}(z), f^{n-1}(x)\right)\right)\right) \cdot \psi\left(d\left(f^{n-1}(z), f^{n-1}(x)\right)\right) \\
& \leq \psi\left(d\left(f^{n-1}(z), f^{n-1}(x)\right)\right) \\
& =\psi\left(d\left(z, f^{n-1}(x)\right)\right) .
\end{aligned}
$$

Consequently, the sequence $\left\{\gamma_{n}\right\}$ defined by $\gamma_{n}=\psi\left(d\left(z, f^{n}(x)\right)\right)$ is nonnegative and nonincreasing and so

$$
\lim _{n \rightarrow \infty} \psi\left(d\left(z, f^{n}(x)\right)\right)=\gamma \geq 0
$$

Now, we show that $\gamma=0$. Assume that $\gamma>0$. By passing to the subsequences, if necessary, we may assume that $\lim _{n \rightarrow \infty} \beta\left(\gamma_{n}\right)=\lambda$ exists. From (2.5), it follows that $\lambda \gamma=$ $\gamma$ and so $\lambda=1$. Since $\beta \in S$,

$$
\gamma=\lim _{n \rightarrow \infty} \gamma_{n}=\lim _{n \rightarrow \infty} \psi\left(d\left(z, f^{n}(x)\right)\right)=0 .
$$

This is a contradiction and so $\gamma=0$.

Similarly, we can prove that

$$
\lim _{n \rightarrow \infty} \psi\left(d\left(y, f^{n}(x)\right)\right)=0
$$


Finally, from $d(z, y) \leq d\left(z, f^{n}(x)\right)+d\left(f^{n}(x), y\right)$, it follows that

$$
\psi(d(z, y)) \leq \psi\left(d\left(z, f^{n}(x)\right)\right)+\psi\left(d\left(f^{n}(x), y\right)\right)
$$

since $\psi$ is nondecreasing and sub-additive. Therefore, taking $n \rightarrow \infty$, we have $\psi(d(z$, $y))=0$.

It follows that $d(z, y)=0$ and so $z=y$. This completes the proof. $\square$

\section{Applications}

In this section, we show the existence of solution for the following initial-value problem by using Theorems 2.2 and 2.3:

$$
\left\{\begin{array}{lrl}
u_{t}(x, t) & =u_{x x}(x, t)+F\left(x, t, u, u_{x}\right), & -\infty<x<\infty, 0<t \leq T \\
u(x, 0) & =\varphi(x) & -\infty<x<\infty
\end{array}\right.
$$

where we assume that $\phi$ is continuously differentiable and that $\phi$ and $\phi^{\prime}$ are bounded and $F\left(x, t, u, u_{x}\right)$ is a continuous function.

Definition 3.1. By a solution of an initial-boundary-value problem for any $u_{t}=u_{x x}+$ $F\left(x, t, u, u_{x}\right)$ in $\mathbb{R} \times I$, where $I=[0, T]$, we mean a function $u=u(x, t)$ defined in $\mathbb{R} \times$ $I$ such that

(a) $u \in C(\mathbb{R} \times I)$,

(b) $u_{t}, u_{x}$ and $u_{x x} \in C(\mathbb{R} \times I)$,

(c) $u$ and $u_{x}$ are bounded in $\mathbb{R} \times I$,

(d) $u_{t}(x, t)=u_{x x}(x, t)+F\left(x, t, u(x, t), u_{x}(x, t)\right)$ for all $(x, t) \in \mathbb{R} \times I$.

Now, we consider the space

$$
\Omega=\left\{v(x, t): \quad v, v_{x} \in C(\mathbb{R} \times I \text { and }\|v\|<\infty\},\right.
$$

where

$$
\|v\|=\sup _{x \in \mathbb{R}, t \in I}|v(x, t)|+\sup _{x \in \mathbb{R}, t \in I}\left|v_{x}(x, t)\right| .
$$

The set $\Omega$ with the norm $\|\cdot\|$ is a Banach space. Obviously, the space with the metric given by

$$
d(u, v)=\sup _{x \in \mathbb{R}, t \in I}|u(x, t)-v(x, t)|+\sup _{x \in \mathbb{R}, t \in I}\left|u_{x}(x, t)-v_{x}(x, t)\right|
$$

is a complete metric space. The set $\Omega$ can also equipped with a partial order given by

$$
u, v \in \Omega, \quad u \leq v \Leftrightarrow u(x, t) \leq v(x, t), u_{x}(x, t) \leq v_{x}(x, t)
$$

for any $x \in \mathbb{R}$ and $t \in I$. Obviously, $(\Omega, \leq)$ satisfies the condition (2.4) since, for any $u, v \in \Omega$, the functions $\max \{u, v\}$ and $\min \{u, v\}$ are the least upper and greatest lower bounds of $u$ and $v$, respectively.

Taking a monotone nondecreasing sequence $\left\{v_{n}\right\} \subseteq \Omega$ converging to $v$ in $\Omega$, for any $x \in \mathbb{R}$ and $t \in I$,

$$
v_{1}(x, t) \leq v_{2}(x, t) \leq v_{3}(x, t) \leq \cdots \leq v_{n}(x, t) \leq \cdots
$$


and

$$
v_{1_{x}}(x, t) \leq v_{2_{x}}(x, t) \leq v_{3_{x}}(x, t) \leq \cdots \leq v_{n_{x}}(x, t) \leq \cdots .
$$

Further, since the sequences $\left\{v_{n}(x, t)\right\}$ and $\left\{v_{n_{x}}(x, t)\right\}$ of real numbers converge to $v(x$, $t$ ) and $v_{x}(x, t)$, respectively, it follows that, for all $x \in \mathbb{R}, t \in I$ and $n \geq 1$,

$$
v_{n}(x, t) \leq v(x, t)
$$

and

$$
v_{n_{x}}(x, t) \leq v_{x}(x, t)
$$

Therefore, $v_{n} \leq v$ for all $n \geq 1$ and so $(\Omega, \leq)$ with the above mentioned metric satisfies the condition (2.2).

Definition 3.2. A lower solution of the initial-value problem (3.1) is a function $u \in$ $\Omega$ such that

$$
\left\{\begin{array}{l}
u_{t} \leq u_{x x}+F\left(x, t, u, u_{x}\right),-\infty<x<\infty, 0<t \leq T \\
u(x, 0) \leq \varphi(x), \quad-\infty<x<\infty
\end{array}\right.
$$

where we assume that $\phi$ is continuously differentiable $\phi$ and $\phi^{\prime}$ are bounded, the set $\Omega$ is defined in above and $F\left(x, t, u, u_{x}\right)$ is a continuous function.

Theorem 3.3. Consider the problem (3.1) with $F: \mathbb{R} \times I \times \mathbb{R} \times \mathbb{R} \rightarrow \mathbb{R}$ continuous and assume the following:

(1) for any $c>0$ with $|s|<c$ and $|p|<c$, the function $F(x, t, s, p)$ is uniformly Hölder continuous in $X$ and $t$ for each compact subset of $\mathbb{R} \times I$;

(2) there exists a constant $c_{F} \leq\left(T+2 \pi^{\frac{-1}{2}} T^{\frac{1}{2}}\right)^{-1}$ such that

$$
0 \leq F\left(x, t, s_{2}, p_{2}\right)-F\left(x, t, s_{1}, p_{1}\right) \leq c_{F}\left(\ln \left(s_{2}-s_{1}+p_{2}-p_{1}+1\right)\right)
$$

for all $\left(s_{1}, p_{1}\right)$ and $\left(s_{2}, p_{2}\right)$ in $\mathbb{R} \times \mathbb{R}$ with $s_{1} \leq s_{2}$ and $p_{1} \leq p_{2}$;

(3) $F$ is bounded for bounded $s$ and $p$.

Then the existence of a lower solution for the initial-value problem (3.1) provides the existence of the unique solution of the problem (3.1).

Proof. The problem (3.1) is equivalent to the integral equation

$$
u(x, t)=\int_{-\infty}^{\infty} k(x-\xi, t) \varphi(\xi) d \xi+\int_{0}^{t} \int_{-\infty}^{\infty} k(x-\xi, t-\tau) F\left(\xi, \tau, u(\xi, \tau), u_{x}(\xi, \tau)\right) d \xi d \tau
$$

for all $x \in \mathbb{R}$ and $0<t \leq T$, where

$$
k(x, t)=\frac{1}{\sqrt{4 \pi t}} \exp \left\{\frac{-x^{2}}{4 t}\right\}
$$

for all $x \in \mathbb{R}$ and $t>0$. The initial-value problem (3.1) possesses a unique solution if and only if the above integral-differential equation possesses a unique solution $u$ such that $u$ and $u_{x}$ are continuous and bounded for all $x \in \mathbb{R}$ and $0<t \leq T$. 
Define a mapping $F: \Omega \rightarrow \Omega$ by

$$
\begin{aligned}
(F u)(x, t)= & \int_{-\infty}^{\infty} k(x-\xi, t) \varphi(\xi) d \xi \\
& +\int_{0}^{t} \int_{-\infty}^{\infty} k(x-\xi, t-\tau) F\left(\xi, \tau, u(\xi, \tau), u_{x}(\xi, \tau)\right) d \xi d \tau
\end{aligned}
$$

for all $x \in \mathbb{R}$ and $t \in I$. Note that, if $u \in \Omega$ is a fixed point of $\mathbf{F}$, then $u$ is a solution of the problem (3.1).

Now, we show that the hypothesis in Theorems 2.2 and 2.3 are satisfied. The mapping $F$ is nondecreasing since, by the hypothesis, for $u \geq v$,

$$
F\left(x, t, u(x, t), u_{x}(x, t)\right) \geq F\left(x, t, v(x, t), v_{x}(x, t)\right) .
$$

By using that $k(x, t)>0$ for all $(x, t) \in \mathbb{R} \times(0, T]$, we conclude that

$$
\begin{aligned}
(F u)(x, t)= & \int_{-\infty}^{\infty} k(x-\xi, t) \varphi(\xi) d \xi \\
& +\int_{0}^{t} \int_{-\infty}^{\infty} k(x-\xi, t-\tau) F\left(\xi, \tau, u(\xi, \tau), u_{x}(\xi, \tau)\right) d \xi d \tau \\
\geq & \int_{-\infty}^{\infty} k(x-\xi, t) \varphi(\xi) d \xi+\int_{0}^{t} \int_{-\infty}^{\infty} k(x-\xi, t-\tau) F\left(\xi, \tau, v(\xi, \tau), v_{x}(\xi, \tau)\right) d \xi d \tau \\
= & (F v)(x, t)
\end{aligned}
$$

for all $x \in \mathbb{R}$ and $t \in I$. Besides, we have

$$
\begin{aligned}
& |(F u)(x, t)-(F v)(x, t)| \\
\leq & \int_{0}^{t} \int_{-\infty}^{\infty} k(x-\xi, t-\tau)\left|F\left(\xi, \tau, u(\xi, \tau), u_{x}(\xi, \tau)\right)-F\left(\xi, \tau, v(\xi, \tau), v_{x}(\xi, \tau)\right)\right| d \xi d \tau \\
\leq & \int_{0}^{t} \int_{-\infty}^{\infty} k(x-\xi, t-\tau) \cdot c_{F} \ln \left(u(\xi, \tau)-v(\xi, \tau)+u_{x}(\xi, \tau)-v_{x}(\xi, \tau)+1\right) d \xi d \tau \\
\leq & c_{F} \cdot \ln (d(u, v)+1) \int_{0}^{t} \int_{-\infty}^{\infty} k(x-\xi, t-\tau) d \xi d \tau \\
\leq & c_{F} \cdot \ln (d(u, v)+1) \cdot T
\end{aligned}
$$

for all $u \geq v$. Similarly, we have

$$
\begin{aligned}
\left|\frac{\partial F u}{\partial x}(x, t)-\frac{\partial F v}{\partial x}(x, t)\right| & \leq c_{F} \cdot \ln (d(u, v)+1) \int_{0}^{t} \int_{-\infty}^{\infty}\left|\frac{\partial k}{\partial x}(x-\xi, t-\tau)\right| d \xi d \tau \\
& \leq c_{F} \cdot \ln (d(u, v)+1) \cdot 2 \pi^{\frac{-1}{2}} T^{\frac{1}{2}}
\end{aligned}
$$

Combining (3.2) with (3.3), we obtain

$$
d(F u, F v) \leq c_{F}\left(T+2 \pi^{\frac{-1}{2}} T^{\frac{1}{2}}\right) \ln (d(u, v)+1) \leq \ln (d(u, v)+1),
$$

which implies that

$$
\begin{aligned}
\ln (d(F u, F v)+1) & \leq \ln (\ln (d(u, v)+1)+1) \\
& =\frac{\ln (\ln (d(u, v)+1)+1)}{\ln (d(u, v)+1)} \cdot \ln (d(u, v)+1)
\end{aligned}
$$

Put $\psi(x)=\ln (x+1)$ and $\beta(x)=\frac{\psi(x)}{x}$. Obviously, $\psi:[0, \infty) \rightarrow[0, \infty)$ is continuous, sub-additive, nondecreasing $\left(\psi^{\prime}(x)=\frac{1}{x+1}>0\right)$ and $\psi$ is positive in $(0, \infty)$ with $\psi(0)=0$ and also $\psi(x)<x$ for any $x>0$ and $\beta \in S$. 
Finally, let $\alpha(x, t)$ be a lower solution for (3.1). Then we show that $\alpha \leq F \alpha$. Integrating the following:

$(\alpha(\xi, \tau) k(x-\xi, t-\tau))_{\tau}-\left(\alpha_{\xi}(\xi, \tau) k(x-\xi, t-\tau)\right)_{\xi}+\left(\alpha(\xi, \tau) k_{\xi}(x-\xi, t-\tau)\right)_{\xi}$

$\leq F\left(\xi, \tau, \alpha(\xi, \tau), \alpha_{\xi}(\xi, \tau)\right) k(x-\xi, t-\tau)$

for $-\infty<\xi<\infty$ and $0<\tau<t$, we obtain the following:

$$
\begin{aligned}
\alpha(x, t) & \leq \int_{-\infty}^{\infty} k(x-\xi, t) \varphi(\xi) d \xi+\int_{0}^{t} \int_{-\infty}^{\infty} k(x-\xi, t-\tau) F\left(\xi, \tau, \alpha(\xi, \tau), \alpha_{\xi}(\xi, \tau)\right) d \xi d \tau \\
& =(F \alpha)(x, t)
\end{aligned}
$$

for all $x \in \mathbb{R}$ and $t \in(0, T]$. Therefore, by Theorems 2.2 and $2.3, F$ has a unique fixed point. This completes the proof. $\square$

\section{Acknowledgements}

This research was also supported by Basic Science Research Program through the National Research Foundation of Korea (NRF) funded by the Ministry of Education, Science, and Technology (Grant Number: 2011-0021821).

\section{Author details}

${ }^{1}$ Department of Mathematics, Semnan University, P. O. Box 35195-363, Semnan, Iran ${ }^{2}$ Department of Mathematics Education and the RINS, Gyeongsang National University, Chinju 660-701, Korea

\section{Authors' contributions}

All authors read and approved the final manuscript.

\section{Competing interests}

The authors declare that they have no competing interests.

Received: 4 December 2011 Accepted: 4 May 2012 Published: 4 May 2012

\section{References}

1. Abbas, M, Cho, YJ, Nazir, T: Common fixed point theorems for four mappings in TVS-valued cone metric spaces. J Math Inequal. 5, 287-299 (2011)

2. Agarwal, RP, El-Gebeily, MA, O'regan, D: Generalized contractions in partially ordered metric spaces. Appl Anal. 87, 109-116 (2008). doi:10.1080/00036810701556151

3. Amini-Harandi, A, Emami, H: A fixed point theorem for contraction type maps in partially ordered metric spaces and application to ordinary differential equations. Nonlinear Anal. 72, 2238-2242 (2010). doi:10.1016/j.na.2009.10.023

4. Bhaskar, TG, Lakshmikantham, V: Fixed point theorems in partially ordered metric spaces and applications. Nonlinear Anal. 65, 1379-1393 (2006). doi:10.1016/j.na.2005.10.017

5. Cho, YJ, He, G, Huang, NJ: The existence results of coupled quasi-solutions for a class of operator equations. Bull Korean Math Soc. 47, 455-465 (2010)

6. Cho, YJ, Rhoades, BE, Saadati, R, Samet, B, Shantawi, W: Nonlinear coupled fixed point theorems in ordered generalized metric spaces with integral type. Fixed Point Theory Appl. 2012, 8 (2012). doi:10.1186/1687-1812-2012-8

7. Cho, YJ, Saadati, R, Wang, S: Common fixed point theorems on generalized distance in order cone metric spaces. Comput Math Appl. 61, 1254-1260 (2011). doi:10.1016/j.camwa.2011.01.004

8. Cho, YJ, Shah, MH, Hussain, N: Coupled fixed points of weakly F-contractive mappings in topological spaces. Appl Math Lett. 24, 1185-1190 (2011). doi:10.1016/j.aml.2011.02.004

9. Drici, Z, McRae, FA, Devi, JV: Fixed point theorems in partially ordered metric spaces for operators with PPF dependence. Nonlinear Anal. 7, 641-647 (2007)

10. Dukic, D, Kadelburg, Z, Radenovic, S: Fixed point of Geraghty-type mappings in various generalized metric spaces. Abstr Appl Anal 2011 (2011). Article ID 561245, 13

11. Gordji, ME, Baghani, H, Cho, YJ: Coupled fixed point theorems for contractions in intuitionistic fuzzy normed spaces. Math Comput Model. 54, 1897-1906 (2011). doi:10.1016/j.mcm.2011.04.014

12. Gordji, ME, Ramezani, M: A generalization of Mizoguchi and Takahashi's theorem for single-valued mappings in partially ordered metric spaces. Nonlinear Anal. 74, 4544-4549 (2011). doi:10.1016/j.na.2011.04.020

13. Geraghty, M: On contractive mappings. Proc Amer Math Soc. 40, 604-608 (1973). doi:10.1090/S0002-9939-19730334176-5

14. Graily, E, Vaezpour, SM, Saadati, R, Cho, YJ: Generalization of fixed point theorems in ordered metric spaces concerning generalized distance. Fixed Point Theory Appl. 2011, 30 (2011). doi:10.1186/1687-1812-2011-30

15. Harjani, J, Sadarangani, K: Fixed point theorems for weakly contractive mappings in partially ordered sets. Nonlinear Anal. 71, 3403-3410 (2009). doi:10.1016/j.na.2009.01.240

16. Kadelburg, Z, Pavlovic, M, Radenovic, S: Common fixed point theorems for ordered contractions and quasicontractions in ordered conemetric spaces. Comput Math Appl. 59, 3148-3159 (2010). doi:10.1016/j.camwa.2010.02.039

17. Lakshmikantham, V, Ćirić, Lj: Couple fixed point theorems for nonlinear contractions in partially ordered metric spaces. Nonlinear Anal. 70, 4341-4349 (2009). doi:10.1016/j.na.2008.09.020 
18. Nashine, HK, Kadelburg, Z, Radenovic, S: Coupled common fixed point theorems for $\mathrm{w}^{*}$-compatible mappings in ordered cone metric spaces. Appl Math Comput. 218, 5422-5432 (2012). doi:10.1016/j.amc.2011.11.029

19. Nieto, JJ, Pouso, RL, Rodríguez-López, R: Fixed point theorems in ordered abstract sets. Proc. Amer Math Soc. 135 2505-2517 (2007). doi:10.1090/50002-9939-07-08729-1

20. Nieto, JJ, Rodríguez-López, R: Contractive mapping theorems in partially ordered sets and applications to ordinary differential equations. Order. 22, 223-239 (2005). doi:10.1007/s11083-005-9018-5

21. Nieto, JJ, Rodríguez-López, R: Existence and uniqueness of fixed point in partially ordered sets and applications to ordinary differential equations. Acta Math Sin. 23, 2205-2212 (2007). doi:10.1007/s10114-005-0769-0

22. O'regan, D, Petrusel, A: Fixed point theorems for generalized contractions in ordered metric spaces. J Math Anal Appl. 341, 1241-1252 (2008). doi:10.1016/j.jmaa.2007.11.026

23. Petrusel, A, Rus, IA: Fixed point theorems in ordered L-spaces. Proc Amer Math Soc. 134, 411-418 (2006)

24. Radenović, S, Kadelburg, Z: Generalized weak contractions in partially ordered metric spaces. Comput Math Appl. 60, 1776-1783 (2010). doi:10.1016/j.camwa.2010.07.008

25. Radenović, S, Kadelburg, Z, Jandrlic, D, Jandrlic, A: Some results on weakly contractive maps. Bull Iran Math Soc. (in press)

26. Ran, ACM, Reurings, MCB: A fixed point theorem in partially ordered sets and some applications to matrix equations. Proc Amer Math Soc. 132, 1435-1443 (2004). doi:10.1090/50002-9939-03-07220-4

27. Sintunavarat, W, Cho, YJ, Kumam, P: Common fixed point theorems for c-distance in ordered cone metric spaces. Comput Math Appl. 62, 1969-1978 (2011). doi:10.1016/j.camwa.2011.06.040

28. Sintunavarat, W, Cho, YJ, Kumam, P: Coupled coincidence point theorems for contractions without commutative condition in intuitionistic fuzzy normed spaces. Fixed Point Theory Appl. 2011, 81 (2011). doi:10.1186/1687-1812-201181

doi:10.1186/1687-1812-2012-74

Cite this article as: Gordji et al:: A generalization of Geraghty's theorem in partially ordered metric spaces and applications to ordinary differential equations. Fixed Point Theory and Applications 2012 2012:74.

\section{Submit your manuscript to a SpringerOpen ${ }^{\circ}$ journal and benefit from:}

- Convenient online submission

Rigorous peer review

- Immediate publication on acceptance

- Open access: articles freely available online

- High visibility within the field

- Retaining the copyright to your article

Submit your next manuscript at $\boldsymbol{s p r i n g e r o p e n . c o m ~}$ 